\title{
REUSING OF SODIUM SILICATE AS A RAW MATERIAL IN GLASS INDUSTRY: BY- PRODUCT OF SODIUM BOROHYDRIDE PRODUCTION
}

\author{
Aysel Kantürk \\ Müge Sart \\ Özgül Dere \\ Sabriye Pişkin ${ }^{I}$ \\ ${ }^{\text {I} Y i l d i z ~ T e c h n i c a l ~ U n i v e r s i t y, ~ D e p a r t m e n t ~ o f ~ C h e m i c a l ~ E n g i n e e r i n g, ~ T u r k e y ~}$
}

\begin{abstract}
Global energy and ecology problems continue to grow because of burning of fossil fuels, environmental pollution, decrease of energy sources and difficulties in storing electricity. Hydrogen has great potential to solve these problems as an environmentally clean energy carrier and as a way to reduce reliance on imported energy sources. Hydrogen can be stored and transported safely in the form of sodium borohydride $\left(\mathrm{NaBH}_{4}\right)$ due to its high theoretical hydrogen yield by weight $(10.6 \%)$ in applications where $\mathrm{H}_{2}$ gas is used, e.g., proton exchange membrane (PEM) fuel cells. $\mathrm{NaBH}_{4}$ is synthesized from boron minerals (borax, ulexite, colemanite...) by the thermal-chemical reactions.

The main aim of this paper is the investigation of reusing of $\mathrm{Na}_{2} \mathrm{SiO}_{3}$, obtained from $\mathrm{NaBH}_{4}$ production based on the conversion reaction of borosilicate glass, as a raw material in glass industry. The by-product, was defined as $\mathrm{Na}_{2} \mathrm{SiO}_{3}$ (PDF number: 00-016-0818) by XRD (XRay Diffractometer) technique, was then vitrificated into a glass for utilization. The obtained glass was characterized by scanning electron microscopy with energy dispersive spectroscopy (SEM/EDS) analysis and FT-IR (Fourier Transformer-Infrared spectroscopy) techniques. The results show that by-product $\mathrm{Na}_{2} \mathrm{SiO}_{3}$ can be reused as a raw material in glass industry.
\end{abstract}

\section{KEYWORDS}

Sodium silicate; Reusing; Vitrification; Sodium borohydride; clean energy.

\section{INTRODUCTION}

Sodium borohydride $\left(\mathrm{NaBH}_{4}\right)$, which is known as sodium tetrahydroborate, has attracted attention due to its high theoretical hydrogen content of $10.6 \mathrm{wt} \%$ and the excellent stability of its solution under high $\mathrm{pH}$ value at ambient temperature [1, 2]. Also, $\mathrm{NaBH}_{4}$ is a selective specialty reducing agent used in the manufacture of pharmaceuticals and other organic compounds [3].

It is important to note that $\mathrm{NaBH}_{4}$ can be produced by economical methods to be applied in practical use. According to the several publications, $\mathrm{NaBH}_{4}$ was synthesized by reacting $\mathrm{NaBO}_{2}$ with $\mathrm{MgH}_{2}$ or $\mathrm{Mg}_{2} \mathrm{Si}$ by annealing the mixture of these two compounds under high hydrogen pressure. Also, it was note that $\mathrm{NaBH}_{4}$ can be produced by reaction of $\mathrm{MgH}_{2}$ with $\mathrm{Na}_{2} \mathrm{~B}_{4} \mathrm{O}_{7}$ through ball milling at room temperature [4, 5]. 
In previous study of authors was expressed that process for producing $\mathrm{NaBH}_{4}$, which is based on the conversion reaction of borosilicate glass at temperatures between about $400-500^{\circ} \mathrm{C}$ under high hydrogen pressure. They defined the by-product as sodium silicate $\left(\mathrm{Na}_{2} \mathrm{SiO}_{3}\right)$ [6].

In the present work, reusing of $\mathrm{Na}_{2} \mathrm{SiO}_{3}$, obtained from $\mathrm{NaBH}_{4}$ production based on the conversion reaction of borosilicate glass, as a raw material in glass industry was investigated. The by-product, characterized as $\mathrm{Na}_{2} \mathrm{SiO}_{3}$ (PDF number: 00-016-0818) by XRD (X-Ray Diffractometer) technique, was vitrificated into a glass for utilization. The obtained glass was determined by SEM (Scanning Electron Microscopy) with EDS (Energy Dispersive Spectroscopy) analysis and FT-IR (Fourier Transformer-Infrared spectroscopy) techniques. The analysis results indicate that by-product $\mathrm{Na}_{2} \mathrm{SiO}_{3}$ can be reused as a raw material in glass industry.

\section{EXPERIMENTAL}

\subsection{Material}

The by-product $\left(\mathrm{Na}_{2} \mathrm{SiO}_{3}\right)$ which was obtained from $\mathrm{NaBH}_{4}$ production is based on the conversion reaction of borosilicate glass at temperatures between about $400-500^{\circ} \mathrm{C}$ under high hydrogen pressure. The flow chart of $\mathrm{NaBH}_{4}$ production process is given in Figure 1 .

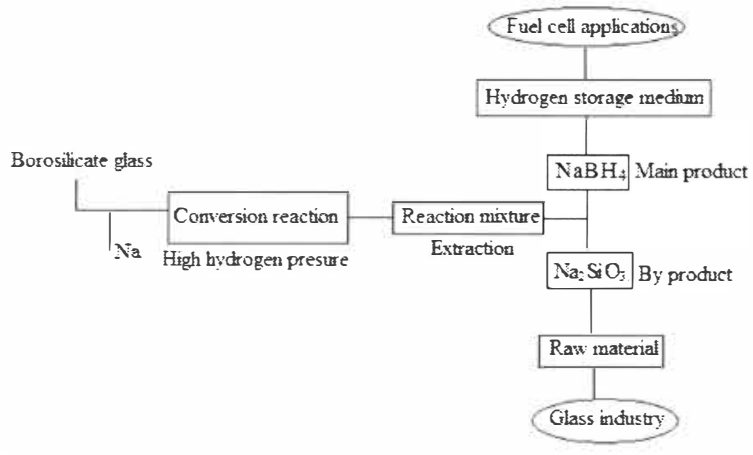

Figure 1. The flow chart of $\mathrm{NaBH}_{4}$ production

After the conversion reaction of borosilicate glass, the resulting reaction product was analyzed by XRD technique for qualitative identification. It was determined that resulting reaction product includes $\mathrm{NaBH}_{4}$ (main product) and $\mathrm{Na}_{2} \mathrm{SiO}_{3}$ (by product). It was extracted with suitable solution to separate $\mathrm{NaBH}_{4}$ from $\mathrm{Na}_{2} \mathrm{SiO}_{3}$. Extraction solution was separated from the by product and remaining reactants by filter paper and was evaporated in the rotary dryer. By-product (see Figure 2) was dried for two hours before the XRD analysis and XRD pattern is given in Figure 5. 


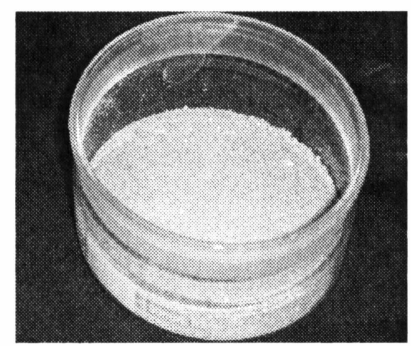

Figure 2. Image of by-product

\subsection{Vitrification}

In this study, the potentiality of by-product vitrification without any additives was examined for utilizing as a raw material in glass industry. The by-product was subject to a vitrification process to production of glass in a high temperature furnace. The mineralogical structure and the chemical properties of the obtained glass were carried out by SEM-EDS and FT-IR analysis. The images of obtained glass are shown in Figure 3.
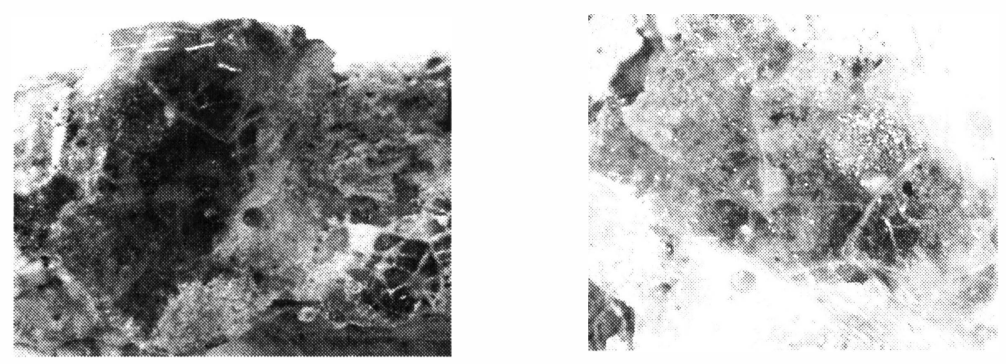

Figure 3. Images of obtained glass after vitrification of by-product

\subsection{Characterization}

Crystalline structure of by-product obtained by the $\mathrm{NaBH}_{4}$ process was investigated by XRD technique that reveals detailed information about the chemical composition and crystallographic structure of materials. Analysis was made by using a Philips PAnalytical $\mathrm{X}$ 'Pert Pro diffractometer using $\mathrm{CuK} \alpha$ radiation $(45 \mathrm{kV}$ and $40 \mathrm{~mA})$ and recorded at room temperature with a diffraction angle from $0^{\circ}$ to $90^{\circ}$ at $0.02^{\circ}(2 \theta)$ step size. Phase identification was performed using the XRD library available on the data system. XRD pattern of by product is given in Figure 5.

Scanning electron microscope (JEOL JSM-5910LV) with a type of electron microscope capable of producing high-resolution images of a sample surface was used to determine the microstructure of obtained glass at the energy of the electron beam of $25 \mathrm{kV}$. Quantitative 
chemical analyses of the glass obtained by vitrification of by-product were also performed using an X-Ray energy dispersive spectrometer (EDS) coupled to the SEM. The SEM images of obtained glass at 500 and 2000 magnifications are given in Figure 4 (a) and (b).

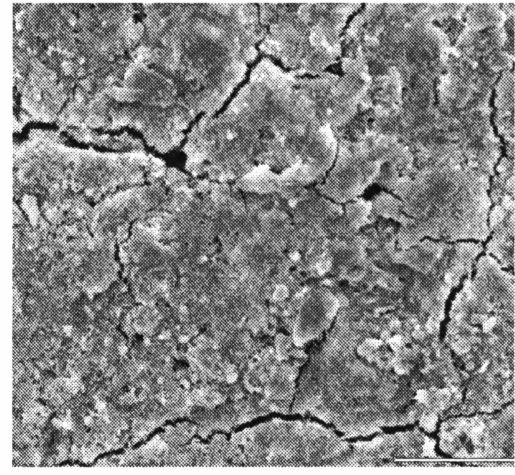

(a)

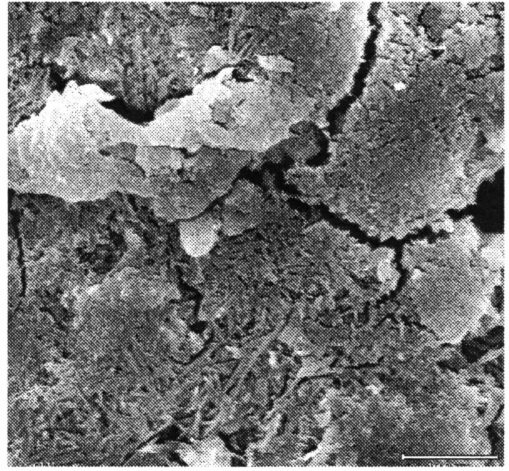

(b)

Figure 4. SEM images of obtained glass: (a) $\times 500($ bar $=50 \mu \mathrm{m}) ;(b) \times 2000(\mathrm{bar}=10 \mu \mathrm{m})$

The chemical bond of obtained glass was investigated by using the technique of Attenuated Total Reflectance (ATR) of FT-IR Spectroscopy (Perkin Elmer Spectrum One). The spectrum was collected over the 4000 to $650 \mathrm{~cm}^{-1}$ wavenumber range, at a resolution of $8 \mathrm{~cm}^{-1}$. FT-IR spectrum is shown in Figure 7. All the absorption bands are marked and explained in detail.

\section{RESULT AND DISCUSSION}

XRD pattern of the by-product is given in Figure 3. The XRD pattern indicated that byproduct was defined as $\mathrm{Na}_{2} \mathrm{SiO}_{3}$. Also, XRD result showed that nonexistence of $\mathrm{NaBH}_{4}$ in byproduct.

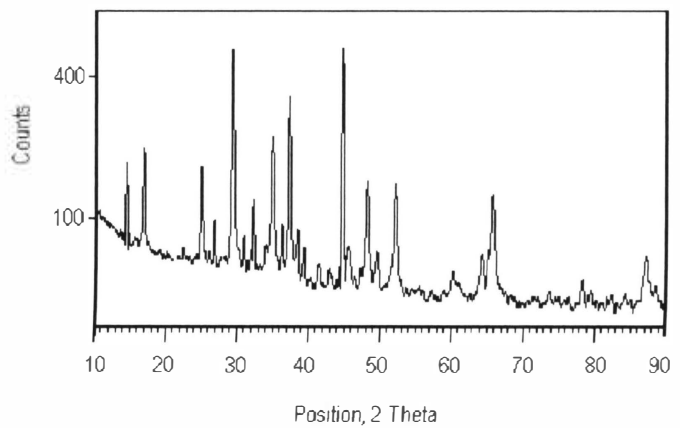

Figure 5. XRD pattern of the by-product 
Morphological observations on a microscopic scale at different magnifications by SEM (see Figure $3(a)$ and $(b)$ ) showed formation of amorphous phase. The EDS spectra in Figure $6(b)$ and (c) were collected from the enclosed area 1 and 2 in Figure 6 (a), respectively. According to the EDS spectrums, the chemical composition of obtained glass is calculated as $48.12 \% \mathrm{O}$, $51.88 \% \mathrm{Si}$ in Figure 6 (b), while the chemical composition of obtained glass is calculated as $33.85 \% \mathrm{O}, 9.75 \% \mathrm{Na}$ and $56.40 \% \mathrm{Si}$ in Figure 6 (c). The bubbles in the SEM image (enclosed area 1) are associated with $\mathrm{SiO}_{2}$ content on $100 \mu \mathrm{m}$ scale.
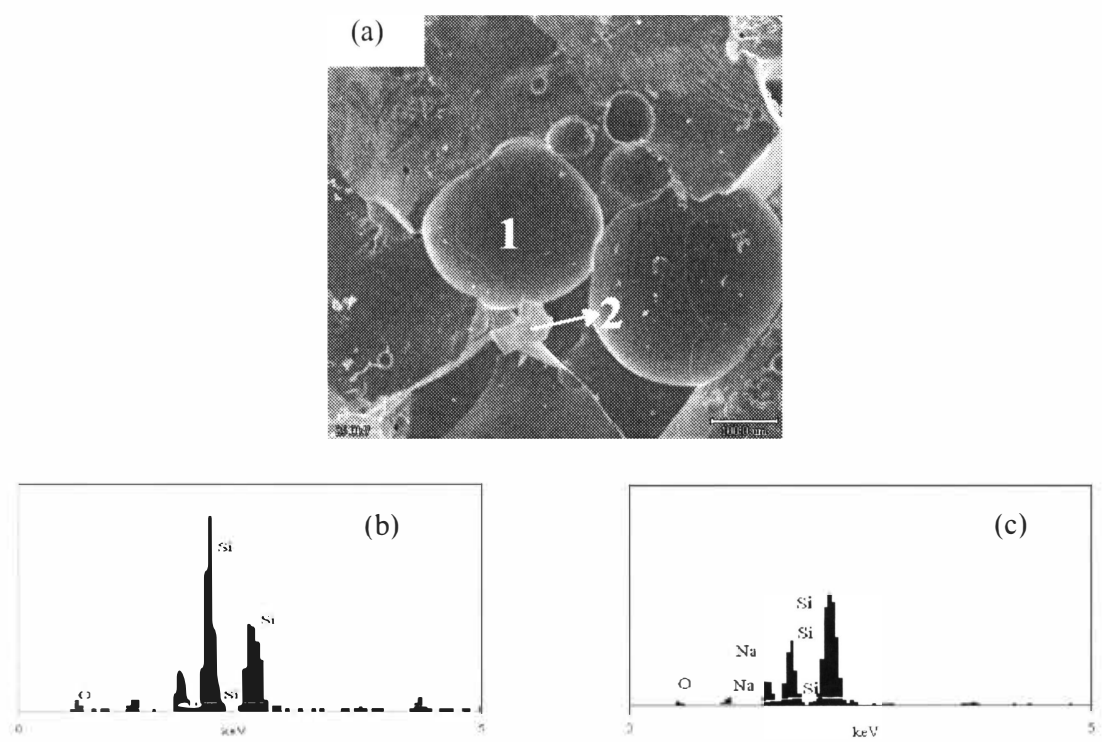

Figure 6. (a) The SEM image of obtained glass with EDS analysis, $\times 150$ magnitude, $(b, c)$ corresponding EDS spectra acquired from the areas of 1 and 2 in (a).

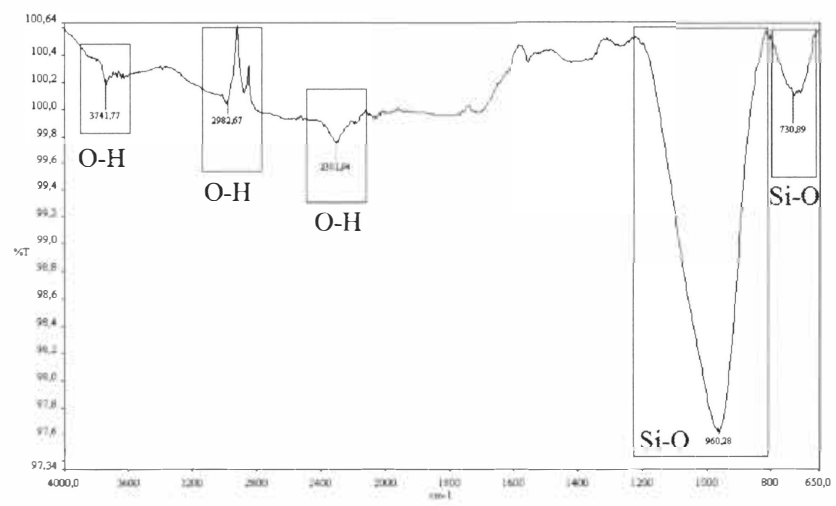

Figure 7. FT-IR spectrum of obtained glass 


\section{CONCLUSION}

This paper presents investigation of reusing of $\mathrm{Na}_{2} \mathrm{SiO}_{3}$, obtained by $\mathrm{NaBH}_{4}$ production, as a raw material in glass industry. $\mathrm{Na}_{2} \mathrm{SiO}_{3}$ was vitrified without any additives in high temperature furnace. Detailed morphological and chemical analyses of glass obtained were carried out by FT-IR and SEM-EDS analysis. In a conclusion, obtained glass can be used for decorative purpose because of greenish colour.

\section{ACKNOWLEDGMENTS}

The authors would like to thank for the financial sport of The Prime Ministry State Planning Organization (Project No: 23-DPT-07-01-02) is gratefully acknowledged.

\section{REFERENCES}

[1] Schlinger, H. I., Brown, H. C., Finholt, A. E., Gilbert, J. R., Hoekstra, H. R. ve Hyde, E. K., 1953. Sodium borohydrite, its hydrolysis and its use as a reducing agent and in the generation of hydrogen, Journal of American Chemical Society, 75, 215-219.

[2] Kim, J., Lee, H., Han, S., Kim, H., Song, M., Lee, J., 2004. Production of hydrogen from sodium borohydride in alkaline solution: development of catalyst with high performance, International Journal of Hydrogen Energy, 29, 263-267.

[3] http://en.wikipedia.org

[4] Kojima, Y., Haga, T., 2003. Recycling process of sodium metaborate to sodium. borohydride, International Journal of Hydrogen Energy, 28, 989-993.

[5] Li, Z. P., Morgazaki, N., Liu, B. H., Suda S., 2003. Preparation of sodium borohydride by the reaction of $\mathrm{MgH}_{2}$ with dehydrate borax through ball milling at room temperature, Journal of Alloys Compounds, 349, 232-236.

[6] Kantürk, A., Pişkin, S. Innovation in sodium borohydride production process from borosilicate glass with sodium under hydrogen atmosphere: high hydrogen process, International Journal of Hydrogen Energy. In Press. 